\title{
Bilevel Programming Model of Private Capital Investment in Urban Public Transportation: Case Study of Jinan City
}

\author{
Yunqiang Xue, ${ }^{1,2,3}$ Hongzhi Guan, ${ }^{1,2}$ Jonathan Corey, ${ }^{3,4}$ Huanmei Qin, ${ }^{2}$ \\ Yan $\mathrm{Han}^{2}$ and Jiaqi $\mathrm{Ma}^{5}$ \\ ${ }^{1}$ College of Architecture and Civil Engineering, Beijing University of Technology, Beijing 100124, China \\ ${ }^{2}$ Beijing Key Lab of Traffic Engineering, Beijing University of Technology, Beijing 100124, China \\ ${ }^{3}$ ART-Engines Transportation Research Lab, University of Cincinnati, Cincinnati, OH 45221, USA \\ ${ }^{4}$ College of Engineering \& Applied Science, University of Cincinnati, Cincinnati, OH 45221, USA \\ ${ }^{5}$ Transportation Solutions and Technology Applications Division, Leidos, Inc., Reston, VA 20190, USA
}

Correspondence should be addressed to Yunqiang Xue; xueyunqiang@emails.bjut.edu.cn

Received 16 June 2015; Revised 13 October 2015; Accepted 25 October 2015

Academic Editor: Paolo Crippa

Copyright (C) 2015 Yunqiang Xue et al. This is an open access article distributed under the Creative Commons Attribution License, which permits unrestricted use, distribution, and reproduction in any medium, provided the original work is properly cited.

\begin{abstract}
Increasing public transportation subsidies have created fiscal pressures for governments. To ease this financial pressure, Chinese government strongly encourages private capital investment in public transportation. However, previous private capital investments in public transportation operations have largely failed, mainly due to low ticket fares that cannot support sustainable operations. To address this issue, several previous research projects have developed methods to facilitate private capital investment. The majority of the research focuses on qualitative analysis and value for money analysis. Our research proposed a new method of private capital investment in public transportation operations based on the concept of "passenger value." The feasibility of the proposed method of private investment was analyzed quantitatively by constructing a bilevel programming model. The model was verified based on a sample analysis of Jinan city traffic. Results showed that effective private capital investment increases the total societal benefit from the public transportation system and additionally that the investment method considering "passenger value" is superior to the traditional one. A quantitative tool was provided by the model to evaluate private capital investment effects, design investment policies, and develop further research.
\end{abstract}

\section{Introduction}

Traffic congestion has become a serious obstacle to sustainable urban development. Therefore a common solution to ease traffic congestion has been the development of public transportation [1]. Due to their impact on societal mobility, ticket prices for public transportation must be kept affordable. Thus, fiscal subsidies are needed to maintain normal operation of public transportation systems. With the increase in operating costs, the financial burden on governments is also increasing. Governments at all levels are facing the problem of keeping transit fares at low levels while managing limited financial resources and providing good travel service. Fortunately, private capital provides potential solutions to the problem.
The experiences of developed countries throughout the world [2-6] show that the best way out of the dilemma for public transportation is to end the monopoly of governmental control over public transportation and establish competition between public and private sectors. A consensus has been formed among industries and governments to introduce private operation in urban public transportation industry. Since the 1980s, China has also issued related documents and taken measures [7-10] to encourage private capital investment in the construction and operation of public transportation and had seen some successes. However, private capital investment in public transportation operations largely failed $[11,12]$ because low ticket prices cannot generate sufficient revenue. Therefore, the feasibility of private capital 
investment must be quantitatively evaluated so that reasonable investment policies to improve the success rate can be developed.

Researchers [2-6, 11-15] have rarely neither quantitatively analyzed the effects of private capital involvement in public transportation nor determined the customer resources (herein, customers in public transportation systems are the passengers.) necessary to adequately increase profits from the perspective of customer value. Previous quantitative studies mainly focused on feasibility evaluation using value for money analysis [16] and lacked the value-of-time (VOT) of passengers [17], which is also important due to public necessity of transport. To address the shortcomings of previous studies, existing investment methods were analyzed and a new method of private capital investment in public transportation was developed by considering passenger value in this study. This new method's feasibility was evaluated quantitatively by creating a bilevel programming model. The bilevel programming model validity was verified based on the model characteristics and a case study of Jinan public transportation. Conclusions and further research issues are described in the last section.

\section{Methods of Private Capital Investment in Public Transportation}

2.1. Existing Methods of Private Capital Investment in Public Transportation. In this paper, private capital refers to all domestic capital excluding state/government investment capital and foreign capital. Private investment in transportation industry is mainly concentrated in three areas: infrastructure construction, transportation services, and emerging transportation industry [19]. There are approximately eight types [19] of private capital investment in the transportation industry: financing models such as Build-OperateTransfer (BOT), transportation investment funds, municipal bonds, transportation industrial parks, entrusted loans, comprehensive transportation hubs, transportation public welfare foundations, and transportation asset securitization.

(1) Traditional Financing Models. These models include BuildOperate-Transfer (BOT), Design-Build-Finance-Operate (DBFO), Build-Operate (BO), and Transfer-Operate-Transfer (TOT).

(2) Transportation Investment Funds. They are established for highways, railways, fairways, and other transportation projects separately. Qualified fund trustees are selected and the funds are operated by fund management companies. Local capital is one of the sources of the investment funds.

(3) Municipal Bonds. One type of these bonds is obligation bonds backed by government in fiscal revenue, and it is primarily for the nonprofit public welfare projects (e.g., rural highways). The other type is the special bonds issued by local government for profitable transportation projects, such as railways and airports, and the buyers may be individuals, companies, or other investment organizations.
(4) Transportation Industrial Parks. The main focus is on transportation services and emerging transportation industry, particularly the development of modern logistics parks to attract investment from the society. The industrial parks are primarily funded by private capital, transportation investment funds, and loans with discounted interest rates, and so forth.

(5) Entrusted Loans. The loans are issued, supervised, and recovered by the bank, entrusted by a trustor for its own disposable capital, according to the loan object, purpose, amount, term, and interest rate. The trustor may be the government, public institutions, and private capital.

(6) Comprehensive Transportation Hubs. Transportation passenger stations can be integrated with commercial facilities. Investors are allowed to build transportation infrastructure and gain profits through integrated commercial development at the stations.

(7) Transportation Public Welfare Foundations. Private capital is encouraged and attracted through the transportation public welfare foundations. Transportation agencies, private companies, or individuals may be the original fund investor.

(8) Transportation Asset Securitization. Asset securitization indicates the conversion of illiquid assets to securities that are freely traded in financial markets. For example, the highway companies can be the sponsor and sell assets to Special Purpose Vehicles (SPVs), agencies set up by security firms with high credit rating for risk mitigation. The subject matter of the asserts is the tolling right of constructed highways in the concession period. SPVs pay the highway companies through selling the assets-backed securities to investors. The raised funds are used by highway companies for project construction.

Private capital investment in public transportation is in limit scope, mainly on infrastructure construction and operations. Since investment in infrastructure construction is well-addressed, investment in operations is the focus of the following sections.

2.2. The Investment Method Considering Passenger Value. Seybold et al. [20] stated that the "customer economy" era had come and proposed three principles defining the customer economy: customer-driven marketing strategy, focus on customer relationship, and the great importance of customer experience. Research on customer value is based on three different approaches [21-24]: (1) Customers are regarded as the subjects and enterprises as objects in the value analysis. Understanding and meeting customer demand is the primary task. (2) Enterprises are regarded as the subjects and customers as objects. Attracting and maintaining profitable customers is the primary task. Customer lifetime period is the primary research task. (3) Customers and enterprises are both subjects and objects in the value analysis, known as a customer value exchange study. To achieve a mutually beneficial situation through relationships, partnerships, and alliances is important. 
Research on customer value is mainly in the areas of telecommunications and mobile commerce $[25,26]$; research in the field of transport is rare, mainly focusing on railway customer value classification [27, 28]. Relevant research in the field of public transportation about passenger value is lacking. As users of bus services, passengers form a vast customer base. However, the value of loyal passengers has not been examined. If incentives are created to encourage loyal passengers, more people will be attracted to take buses and more passengers will become valuable loyal customers.

For bus companies, the customer value of passengers ("passenger value" for short in the following section) includes fare income, cash flow income of accounts, and advertisement revenue. The customer value passengers experience includes public transit service, ticket price, and accessibility and quickness which can be measured by time value. Due to the public benefits of bus systems, government purchase public services to supply travel services; it is reasonable to consider the valueof-time (VOT) of passengers [17] as a basis for fiscal subsidy when the public transportation system efficiency is measured. If some profits are given to the bus passengers who take more trips by bus, different customer values of bus passengers could be reflected and more people would be enticed to travel by bus. The biggest difference (shown in Table 1) with and without considering passenger value is utilizing passenger resource, improving profits created from passengers' bus cards, and returning some profits to valuable loyal passengers.

In Table 1, there are two differences in benefits for private capital company with and without considering passenger value. One is that the profit of cash flow in accounts changes from bank interest to investment profit, and the rate of investment profit is higher than that of bank interest, and the other difference is that advertisement profit is increased by e-commerce ads. Costs of not considering passenger value increase due to returns to passengers. If private investment is feasible, increasing income must be greater than increasing expenditures.

The core reason for previous failures of private capital investment in public transportation was a lack of profitability. Therefore, private companies must improve efficiency of resource utilization for higher profits, in addition to following a sound financial system and regulations. The investment method proposed in this paper considers passenger value and generates more revenue by utilizing passenger resource and should be more conducive to sustainable private capital investment in public transportation operation.

\section{Bilevel Programming Model of Private Capital Investment in Public Transportation}

3.1. Bilevel Programming Model [29]. Bilevel programming problem (BLPP), also known as the bilevel optimal problem, is the programming which contains upper and lower levels. The lower level programming is the constraint condition for the upper level. Suppose that the control variable of upper decision-maker is $x=\left(x_{1}, x_{2}, \ldots, x_{n}\right)^{T} \in X \subset$ $R^{n}$. The control variable of the lower decision-maker is $y=\left(y_{1}, y_{2}, \ldots, y_{n}\right)^{T} \in Y \subset R^{m}$. The bilevel programming model (BLPM) is presented as follows:

$$
\begin{array}{rl}
P 1 \min _{x \in X} & F(x, y) \\
\text { s.t. } & G(x, y) \leq 0, y \text { is solved from } P 2 \\
P 2 \min _{y \in Y} & f(x, y) \\
\text { s.t. } & g(x, y) \leq 0 .
\end{array}
$$

Functions $F, f: R^{n 1} \times R^{n 2} \rightarrow R$ are the respective target functions of $P 1$ and $P 2$; vector functions $G: R^{n 1} \times R^{n 2} \rightarrow$ $R^{m 1}$ and $g: R^{n 1} \times R^{n 2} \rightarrow R^{m 2}$ are the respective constraint conditions of $P 1$ and $P 2$.

3.2. BLPM of Private Capital Investment in Public Transportation considering Passenger Value. For optimization analysis of the effects of private capital investment in public transportation, bilevel programming theory was used to establish a quantitative evaluation model. Bilevel programming theory was used because [29, 30] bus systems are complicated systems including decisions at three levels: government officials, bus companies, and travelers. Governments hope that the bus system produces the largest social benefits, while bus companies expect to maximize profits and travelers want to minimize trip cost; each group is at a different hierarchical level. Bus companies make decisions based on management policy constraints, which will influence travelers' mode choices. Travelers will choose suitable traffic modes generally according to travel choice behavior theory, and these travel choices will in turn affect the policy decisions of the government officials. Public transportation travel supply and demand are coordinated to maximize efficiency. The restrictions and relationships between each of these groups can be captured effectively by multilevel programming models; therefore it is appropriate to evaluate the effects of private capital investment through these models. Because public transportation is integral to public welfare, governments do not expect bus companies to maximize profits, although they do seek to meet the minimum income constraints of bus companies [30]. The three-level decision problem can be converted into BLPP with only two target functions. Also, it is more reasonable to consider the value of time of passengers when the public transportation system welfare is measured, because the system welfare includes not only money but also travel time; therefore the generalized trip cost should be considered [17].

There are three basic kinds of public transportation routes: bus, BRT, and rail rapid transit. Private capital enterprise involves in the operation of one or more of these route types and pays government some fee for the involvement. Private capital enterprise enjoys the same government subsidies as state-owned enterprises. Governments will see increased income due to the private capital involvement fee. According to per capita income level (based on international experience, $5 \%$ to $10 \%$ of personal disposable income is a typical level of passenger spending on public transportation) and individual passengers' acceptable spending level, governments set ticket 
TABLE 1: Differences in profits with and without considering passenger value.

\begin{tabular}{lll}
\hline & Not considering passenger value & Considering passenger value \\
\hline $\begin{array}{l}\text { Benefits of } \\
\text { private capital } \\
\text { company }\end{array}$ & Ticket fare & Ticket fare \\
& Adverts of cash flow in accounts (bank interest) & Profits of cash flow in accounts (investment profit) \\
& Government subsidies & Advertisement profits (bus body and platform ads, e-commerce ads) \\
\hline $\begin{array}{l}\text { Costs of private } \\
\text { capital company }\end{array}$ & Fixed cost (including the involvement fees) & Government subsidies \\
\hline
\end{tabular}

price ranges and establish minimum service levels. The goal of upper decision-makers (government officials) is to realize the largest social welfare from the public transportation system (including state-owned bus enterprises surplus, private capital involvement fees, and travelers' surplus (in mainstream economics, "surplus" refers to two related quantities: consumer surplus and producer surplus. Consumer surplus or consumers' surplus is the monetary gain obtained by consumers because consumers want to purchase a product or some service for a price which is less than the highest price they would be willing to pay. Producer surplus is the amount that producers benefit by selling at a market price that is higher than the least price that they would be willing to sell for. Herein, the bus enterprise surplus which is the more the better equals the benefit minus cost, and traveler surplus which is also the more the better for travelers equals the fee bus travelers willing to pay minus the actual cost. From: http://en.wikipedia.org/wiki/Economic_surplus)), and the control variable is ticket price. The lower decision-makers aim to minimize the generalized travel cost (maximize travel utility), and the control variable is service level (departure frequency). The constraint conditions are profit rate and vehicle capacity limits. It is necessary to ensure that private capital enterprise has stable earnings and customer resources.

3.2.1. Objective Functions. Bus operators' surplus is as follows:

$$
\begin{aligned}
S_{\text {without }}^{0}(f, F)= & \sum_{i=1}^{n} f_{i} Q_{i}+\sum_{i=1}^{n} B_{\text {subsidy }}^{i}+\sum_{i=1}^{n} B_{\text {other }}^{i} \\
& -C_{\text {without }}^{0}(F), \\
S_{\text {private }}^{0}(f, F)= & \sum_{i=n+1}^{m} f_{i} Q_{i}+\sum_{i=n+1}^{m} B_{\text {subsidy }}^{i}+\sum_{i=n+1}^{m} B_{\text {other }}^{i} \\
& +\varphi\left(T, \sum_{i=n+1}^{m} Q_{i} \cdot M_{\text {account }}^{i}\right) \\
& -C_{\text {private }}^{0}(F)-B_{\text {private }} \\
& -C_{\text {private }}^{0}\left(Q_{\text {private }}\right),
\end{aligned}
$$

where $\varphi$ is a beneficial function, is related with time " $T$ ", passenger flow " $Q$ ", and account balance " $M_{\text {account }}$ ". The function can be a linear function, or nonlinear function. In case study, it is treated as the product of " $Q$ " and " $M$ " under fixed time " $T$ ". $M_{\text {account }}^{i}$ is the average account balance of bus card in route $i . f_{i}$ is the ticket price of bus route $i . F$ is departure frequency. $B_{\text {subsidy }}^{i}$ is the subsidy of bus route $i$. $B_{\text {other }}^{i}$ is the subsidy of bus route $i$.

Traveler's surplus is as follows:

$$
\begin{aligned}
S^{t}(f, F)= & \sum_{i} \sum_{j} \int_{0}^{D_{i j}} f_{i j}(d) d w-\sum_{i=1}^{m} f_{i} Q_{i} \\
& +C_{\text {private }}^{0}\left(Q_{\text {private }}\right),
\end{aligned}
$$

where $S^{t}$ is surplus of public transportation travelers and equals the cost that bus travelers are willing to pay for the service minus the actual cost, $D_{i j}$ is public transportation travel demand under $O-D$ (Origin-Destination) pair $i$ and $j$ and is a function of ticket price $f$ and bus service $F$ (departure frequency), $D=D(f, F), f(d)$ is the inverse function of public transportation demand and reflects the corresponding price and service corresponding to demand $D, C_{\text {private }}^{0}$ is the returns to passengers by the private capital enterprise, $m$ is the number of total public transit lines, and $n$ is the number of state-owned lines.

Therefore, the upper objective function is

$$
\begin{aligned}
\max _{f} S(f, F)= & S_{\text {bus }}^{0}(f, F)+B_{\text {private }}+S^{t}(f, F) \\
= & \sum_{i} \sum_{j} \int_{0}^{D_{i j}} f_{i j}(d) d w+B_{\text {private }} \\
& +C_{\text {private }}^{0}\left(Q_{\text {private }}\right)+\sum_{i=1}^{n} B_{\text {subsidy }}^{i} \\
& +\sum_{i=1}^{n} B_{\text {private }}^{i}-\sum_{i=n+1}^{m} f_{i} Q_{i}-C_{\text {without }}^{0}(F) .
\end{aligned}
$$

The lower objective function is

$$
\begin{aligned}
& \min _{F} \operatorname{TC}(S)=\sum_{i} Q_{i} C_{i}^{t}-C_{\text {private }}^{0}\left(Q_{\text {private }}\right)=\sum_{i} f_{i} Q_{i} \\
& +\left[\beta_{\text {bustravel }}\left(\sum Q_{\text {bus }} T_{\text {bustravel }}\right)\right. \\
& +\beta_{\text {buswait }}\left(\sum Q_{\text {bus }} T_{\text {buswait }}\right) \\
& \left.+\beta_{\text {buswalk }}\left(\sum Q_{\text {bus }} T_{\text {buswalk }}\right)\right] \\
& +\left[\beta_{\text {brttravel }}\left(\sum Q_{\text {brt }} T_{\text {brttravel }}\right)\right.
\end{aligned}
$$




$$
\begin{aligned}
& +\beta_{\text {brtwait }}\left(\sum Q_{\text {brt }} T_{\text {brtwait }}\right) \\
& \left.+\beta_{\text {brtwalk }}\left(\sum Q_{\text {brt }} T_{\text {brtwalk }}\right)\right]-C_{\text {private }}^{0}\left(Q_{\text {private }}\right) \\
& +\left[\beta_{\text {subwaytravel }}\left(\sum Q_{\text {subway }} T_{\text {subwaytravel }}\right)\right. \\
& +\beta_{\text {subwaywait }}\left(\sum Q_{\text {subway }} T_{\text {subwaywait }}\right) \\
& \left.+\beta_{\text {subwaywalk }}\left(\sum Q_{\text {subway }} T_{\text {subwaywalk }}\right)\right]
\end{aligned}
$$

where $\mathrm{TC}(S)$ is trip cost of public transportation under private capital investment method $S, Q_{i}$ is volume of route $i, C_{i}^{t}$ is generalized travel cost of route $i, \beta_{\text {bustravel }}$ is travel time value of bus (yuan/hour), $T_{\text {bustravel }}$ is travel time by bus, $\beta_{\text {buswait }}$ is wait time value of bus (yuan/hour), $T_{\text {buswait }}$ is wait time of bus, $\beta_{\text {buswalk }}$ is walk time value of bus (yuan/hour), $T_{\text {buswalk }}$ is walk time of bus, $\beta_{\text {brttravel }}$ is travel time value of
BRT (yuan/hour), $T_{\text {brttravel }}$ is travel time of BRT, $\beta_{\text {brtwait }}$ is wait time value of BRT (yuan/hour), $T_{\text {brtwait }}$ is wait time of BRT, $\beta_{\text {brtwalk }}$ is walk time value of BRT (yuan/hour), $T_{\text {brtwalk }}$ is walk time of BRT, $\beta_{\text {subwaytravel }}$ is travel time value of subway (yuan/hour), $T_{\text {subwaytravel }}$ is travel time of subway, $\beta_{\text {subwaywait }}$ is wait time value of subway (yuan/hour), $T_{\text {subwaywait }}$ is wait time of Subway, $\beta_{\text {subwaywalk }}$ is walk time value of Subway, and $T_{\text {subwaywalk }}$ is walk time of subway.

3.2.2. Constraint Conditions. Ticket price constraint is as follows: ticket price range of route $i$ is set by government according to the ratio of public transportation cost and accounts for personal disposable income and the passengers' acceptable spending level. Consider

$$
f_{i}^{\min } \leq f_{i} \leq f^{\max } .
$$
follows:

$$
\begin{aligned}
& \frac{\sum_{i=n+1}^{m} f_{i} Q_{i}+\varphi\left(T, Q_{\text {private }}, M_{\text {account }}\right)+\sum_{i=n+1}^{m} B_{\text {subsidy }}^{i}+\sum_{i=n+1}^{m} B_{\text {other }}^{s}-C_{\text {private }}^{0}(F)-C_{\text {private }}^{0}\left(Q_{\text {private }}\right)-B_{\text {private }}}{C_{\text {private }}^{0}(F)+C_{\text {private }}^{0}\left(Q_{\text {private }}\right)+B_{\text {private }}} \geq r_{\text {private }} \\
& \quad>r_{\text {bank }} \text {, }
\end{aligned}
$$

where $r_{\text {bank }}$ is rate of bank interest and $r_{\text {private }}$ is the minimum profit rate the private capital company can accept.

The departure frequency constraint is as follows:

$$
F_{i}^{\min } \leq F_{i} \leq \frac{N T_{i}}{\left(2 r t_{i}\right)},
$$

where $N T_{i}$ is the largest number of vehicles for route $i$ and $r t_{i}$ is the average travel time of route $i$ (hour).

The vehicle capacity constraint is as follows:

$$
q_{i} \leq \mathrm{TCap}_{i}
$$

where $T \mathrm{Cap}_{i}$ is the maximum capacity of vehicle in route $i$.
The constraint of traffic demand is as follows:

$$
Q=\sum_{i=1}^{m} Q_{i}^{*}\left(f_{i}, F_{i}\right),
$$

where $Q_{i}^{*}$ is passenger flow of route $i$.

3.2.3. BLPM of Private Capital Investment in Public Transportation considering Passenger Value. The bilevel programming model of private capital investment in public transportation is established as follows based on integration of (4)-(10), where ticket price and departure frequency are as variables. Consider

$$
\begin{array}{ll}
\max _{f} & S(f, F)=\sum_{i} \sum_{j} \int_{0}^{D_{i j}} f_{i j}(d) d w+B_{\text {private }}+C_{\text {private }}^{0}\left(Q_{\text {private }}\right)+\sum_{i=1}^{n} B_{\text {subsidy }}^{i}+\sum_{i=1}^{n} B_{\text {other }}^{i}-\sum_{i=n+1}^{m} f_{i} Q_{i}-C_{\text {without }}^{0}(F) \\
\text { s.t. } & f_{i}^{\min } \leq f_{i} \leq f^{\max } \\
& r_{\text {bank }} \leq r_{\text {private }} \\
& \leq \frac{\sum_{i=n+1}^{m} f_{i} Q_{i}+\varphi\left(T, Q_{\text {private }}, M_{\text {account }}\right)+\sum_{i=n+1}^{m} B_{\text {subsidy }}^{i}+\sum_{i=n+1}^{m} B_{\text {other }}^{s}-C_{\text {private }}^{0}(F)-C_{\text {private }}^{0}\left(Q_{\text {private }}\right)-B_{\text {private }}}{C_{\text {private }}^{0}(F)+C_{\text {private }}^{0}\left(Q_{\text {private }}\right)+B_{\text {private }}} \\
& \min _{F} \quad \mathrm{TC}(S)=\sum_{i} Q_{i} C_{i}^{t}-C_{\text {private }}^{0}\left(Q_{\text {private }}\right) \\
\text { s.t. } & F_{i}^{\min } \leq F_{i} \leq \frac{N T_{i}}{\left(2 r t_{i}\right)}
\end{array}
$$




$$
\begin{aligned}
& q_{i} \leq \operatorname{TCap}_{i} \\
& Q=\sum_{i=1}^{m} Q_{i}^{*}\left(f_{i}, F_{i}\right),
\end{aligned}
$$

where $M_{\text {account }}$ is the average account balance of bus card.

The nonlinear disaggregate model $[31,32]$ will be adopted for traffic mode choice in the lower level model, so the BLPM is NP-hard problem, and the model characteristics should be analyzed. A solution algorithm should also be designed.

The disaggregate model $[31,32]$ is based on the hypothesis that travelers always choose the maximal utility project in a specific condition. Scholars [31-36] have researched many traffic problems using disaggregate models with good results, and the theory is robust at present. Based on the random utility theory, the traveler's utility function can be written in the following form:

$$
U_{\text {in }}=V_{\text {in }}+\varepsilon_{\text {in }}
$$

where $V_{i n}$ is the deterministic component of utility $U_{i}$ for traveler $n$ and $\varepsilon_{i n}$ is a random component of utility $U_{i}$ for traveler $n$.

The multinomial logit choice model is the basic Logit Model, the random component $\varepsilon_{i n}$ in (18) follows the Gumbel distribution, independently and identically across alternatives, and the probability that traffic mode $i$ will be chosen by traveler $n$ is written as follows:

$$
P_{\text {in }}=\frac{\exp \left(\theta V_{\text {in }}\right)}{\sum_{i=1}^{J} \exp \left(\theta V_{\text {in }}\right)}, \quad i=1,2, \ldots, J
$$

where $\theta$ is a parameter and $J$ is a set of available traffic mode alternatives for travelers. The parameter $\theta$ can be estimated by using the Maximum Likelihood and Newton-Raphson method.

\section{Model Characteristics and Solution Algorithm}

4.1. Model Characteristics. In order to simplify the derivation process, only two kinds of transit routes are considered in the section, and passenger flow is distributed between BRT and conventional public bus based on the Binary Logit Model. Supposing private capital investment in BRT, only the subscripts are changed for the case of private capital investment in bus. Some notations are shown below for simplicity:

$$
\begin{aligned}
U_{\text {brt }}= & \sum \theta_{\text {brt }}^{i} T_{\text {brt }}^{i} \\
= & \theta_{\text {brt }} f_{\text {brt }}+\theta_{\text {brtwait }} \cdot \frac{60}{\left(2 \cdot F_{\text {brt }}\right)}+\theta_{\text {brttravel }} \\
& \cdot T_{\text {brttravel }}+\theta_{\text {brtwalk }} \cdot T_{\text {brtwalk }}+C_{\text {brtconstant }},
\end{aligned}
$$

$$
\begin{aligned}
U_{\text {bus }}= & \sum \theta_{\text {bus }}^{i} T_{\text {bus }}^{i} \\
= & \theta_{\text {bus }} f_{\text {bus }}+\theta_{\text {buswait }} \cdot \frac{60}{\left(2 \cdot F_{\text {bus }}\right)}+\theta_{\text {bustravel }} \\
& \cdot T_{\text {bustravel }}+\theta_{\text {buswalk }} \cdot T_{\text {buswalk }}+C_{\text {busconstant }} \cdot
\end{aligned}
$$

The two notations represent, respectively, utilities of BRT and bus travel, where $\theta$ is parametric coefficient of the Logit Model and $T$ is an influent parameter including ticket price, travel time, wait time, walk time to stop, and constants. Consider

$$
\begin{aligned}
C_{\text {brt }}^{T}= & \sum \beta_{\text {brt }}^{i} T_{\text {brt }}^{i} \\
= & f_{\text {brt }}+\beta_{\text {brtwait }} \cdot \frac{60}{\left(2 \cdot F_{\text {brt }}\right)}+\beta_{\text {brttravel }} \cdot T_{\text {brttravel }} \\
& +\beta_{\text {brtwalk }} \cdot T_{\text {brtwalk }} \\
C_{\text {bus }}^{T}= & \sum \beta_{\text {bus }}^{i} T_{\text {bus }}^{i} \\
= & f_{\text {bus }}+\beta_{\text {buswait }} \cdot \frac{60}{\left(2 \cdot F_{\text {bus }}\right)}+\beta_{\text {bustravel }} \cdot T_{\text {bustravel }} \\
& +\beta_{\text {buswalk }} \cdot T_{\text {buswalk }}
\end{aligned}
$$

The above notations are generalized travel costs of BRT and bus and composed of ticket fare, travel time, wait time, and walk time, and $\beta$ is the related value of time.

$M_{\text {return }}=M_{\text {account }} r_{\text {folk }} r_{\text {return }}$ is the returned profits, where $M_{\text {account }}$ is account balance, $r_{\text {folk }}$ is profit rate of account balance, and $r_{\text {return }}$ is the ratio of profits returned to passengers.

Lemma 1 (see $[37,38])$. Suppose that there exits second continuous partial derivative for $f(x, y)$ in domain $D$. Denote $A=f_{x x}^{\prime \prime}(x, y)$ and $B=f_{x y}^{\prime \prime}(x, y)$; then

(1) $f(x, y)$ is concave function if $A<0$, and $A C-B^{2} \geq 0$ in regional $D$;

(2) $f(x, y)$ is convex function if $A>0$, and $A C-B^{2} \geq 0$ in regional $D$.

Proposition 2. The lower objective function is convex if $U_{b r t} \geq$ $U_{b u s}, C_{b r t}^{T}-C_{b u s}^{T} \leq M_{\text {return }}$. That is, if BRT is more attractive than bus and the difference between BRT and Bus is less than profits returned to passengers, the lower objective function is convex. 
Proof. According to Logit Model, the lower objective function can be written as follows:

$$
\begin{aligned}
\mathrm{TC}(S)_{F}= & \sum_{i} Q_{i} C_{i}^{t}-C_{\text {private }}^{0}\left(Q_{\text {private }}\right) \\
= & Q \frac{e^{U_{\text {brt }}}}{\sum_{i \in J} e^{U_{i}}} C_{\text {brt }}^{T}+Q \frac{e^{U_{\text {bus }}}}{\sum_{i \in J} e^{U_{i}}} C_{\text {bus }}^{T} \\
& -Q \frac{e^{U_{\text {brt }}}}{\sum_{i \in J} e^{U_{i}}} M_{\text {return }} .
\end{aligned}
$$

The first- and second-order partial derivatives of TC $(S)$ are taken with respect to $F$ to get the values of $A, B$, and $C$. Consider

$$
\begin{aligned}
& A=\frac{\partial^{2} \mathrm{TC}(S)}{\partial^{2} F_{\mathrm{brt}}}=\frac{30 Q}{\left(e^{U_{\mathrm{brt}}}+e^{U_{\mathrm{bus}}}\right)^{2}}\left(\frac{e^{U_{\mathrm{brt}}}}{F_{\mathrm{brt}}^{4}}\right) \\
& \left\{\left[\frac{e^{U_{\text {brt }}}-e^{U_{\text {bus }}}}{\left(e^{U_{\text {brt }}}+e^{U_{\text {bus }}}\right)^{2}} \cdot 30 \cdot \theta_{\text {brtwait }}-2 F_{\text {brt }}\right]\right. \\
& \cdot\left[e^{U_{\text {bus }}} \theta_{\text {brtwait }} \cdot\left(C_{\text {brt }}^{T}-C_{\text {bus }}^{T}-M_{\text {return }}\right)\right] \\
& +2 F_{\text {brt }}\left(e^{U_{\text {brt }}}+e^{U_{\text {bus }}}\right) \beta_{\text {brtwait }} \\
& \left.+60 \beta_{\text {brtwait }} \theta_{\text {brtwait }} e^{U_{\text {bus }}}\right\} \text {, } \\
& B=\frac{\partial^{2} \mathrm{TC}(S)}{\partial F_{\text {brt }} \partial F_{\text {bus }}}=\frac{30 Q}{\left(e^{U_{\text {brt }}}+e^{U_{\text {bus }}}\right)^{2}}\left(\frac{e^{U_{\text {brt }}}}{F_{\text {brt }}^{2}}\right)\left(\frac{e^{U_{\text {bus }}}}{F_{\text {bus }}^{2}}\right) \\
& \cdot\left\{\frac{e^{U_{\text {brt }}}-e^{U_{\text {bus }}}}{e^{U_{\text {brt }}}+e^{U_{\text {bus }}}} \cdot 30 \cdot \theta_{\text {brtwait }} \theta_{\text {buswait }}\right. \\
& \cdot\left(C_{\text {brt }}^{T}-C_{\text {bus }}^{T}-M_{\text {return }}\right)-30 \theta_{\text {buswait }} \beta_{\text {brtwait }} \\
& \left.+30 \theta_{\text {brtwait }} \beta_{\text {buswait }}\right\} \text {, } \\
& C=\frac{\partial^{2} \mathrm{TC}(S)}{\partial^{2} F_{\text {bus }}}=\frac{30 Q}{\left(e^{U_{\text {brt }}}+e^{U_{\text {bus }}}\right)^{2}}\left(\frac{e^{U_{\text {bus }}}}{F_{\text {bus }}^{4}}\right) \\
& \left\{\left[\frac{e^{U_{\text {bus }}}-e^{U_{\text {brt }}}}{\left(e^{U_{\text {brt }}}+e^{U_{\text {bus }}}\right)^{2}} \cdot 30 \cdot \theta_{\text {buswait }}-2 F_{\text {bus }}\right]\right. \\
& \cdot\left[e^{U_{\text {brt }}} \theta_{\text {buswait }} \cdot\left(C_{\text {brt }}^{T}-C_{\text {bus }}^{T}-M_{\text {return }}\right)\right] \\
& +2 F_{\text {bus }}\left(e^{U_{\text {brt }}}+e^{U_{\text {bus }}}\right) \beta_{\text {buswait }} \\
& \left.+60 \beta_{\text {buswait }} \theta_{\text {buswait }} e^{U_{\text {brt }}}\right\} \text {. }
\end{aligned}
$$

Evidently, if $e^{U_{\text {brt }}} \geq e^{U_{\text {bus }}}$, and $C_{\text {brt }}^{T}-C_{\text {bus }}^{T} \leq M_{\text {return }}$, that is, if $U_{\text {brt }} \geq U_{\text {bus }}$, and $C_{\text {brt }}^{T}-C_{\text {bus }}^{T} \leq M_{\text {return, }}$, then $A \geq 0, A C-B^{2} \geq 0$. That is to say, if BRT is more attractive than conventional public bus and the difference between
BRT and conventional bus is less than profits returned to passengers, the lower objective function is convex. At this point, the bilevel programming model is converted into a single programming model via KKT [39] conditions.

Therefore, the competition of travel utility and generalized travel cost should be fully considered between routes with private capital investment and ones without private investment, when the strategies for private capital investment in public transportation are designed.

There exits the following proposition about the nature of upper objective function.

Proposition 3. If $U_{b r t} \geq U_{b u s}$, and $\left(e^{U_{b r t}}+e^{U_{b u s}}\right) / 4 \theta_{b r t f e e}\left(e^{U_{b r t}}-\right.$ $\left.e^{U_{\text {bus }}}\right) \leq M_{\text {return }}-M_{\text {subsidy }}-f_{\text {brt }} \leq 0$, the upper objective function is convex function ( $M_{\text {subsidy }}$ is government subsidy). That is, if BRT is more attractive than conventional public bus, the profits returned to passengers are less than government subsidies plus ticket fares, at the same time the difference between profits returned to passengers, and government subsidies plus ticket fares are larger than

$$
\frac{e^{U_{b r t}}+e^{U_{b u s}}}{4 \theta_{b r t f e e}\left(e^{U_{b r t}}-e^{U_{b u s}}\right)}
$$

(the value of (24) is less than zero, $\theta_{\text {brtfee }}$ is parametric coefficient of BRT ticket price in Binary Logit Model) and the upper objective function is convex function.

Proof. Only one OD-pair is considered for convenience, and the passenger flow is denoted as $Q$. The upper object function is decomposed as follows.

The first item $\sum_{i} \sum_{j} \int_{0}^{D_{i j}} f_{i j}(d) d w=\int_{0}^{\mathrm{Q}} f(d) d w$ presents the relevant ticket price and service level (departure frequency) under passenger flow $Q$.

According to the existence theorem of initial functions, the first-order and second-order derivatives of the first item with respect to ticket price are listed below:

$$
\begin{aligned}
& \frac{d}{d f_{\mathrm{brt}}} \int_{0}^{\mathrm{Q}} f(d) d w=f(Q) \cdot Q^{\prime}=f(Q) \cdot k_{\mathrm{brt}}, \\
& \frac{d^{2}}{d^{2} f_{\mathrm{brt}}} \int_{0}^{\mathrm{Q}} f(d) d w=k_{\mathrm{brt}}^{2},
\end{aligned}
$$

where, $k_{\mathrm{brt}}$ is constant;

$$
\begin{aligned}
& \frac{d}{d f_{\text {bus }}} \int_{0}^{Q} f(d) d w=f(Q) \cdot Q^{\prime}=f(Q) \cdot k_{\text {bus }}, \\
& \frac{d^{2}}{d^{2} f_{\text {bus }}} \int_{0}^{Q} f(d) d w=k_{\text {bus }}^{2},
\end{aligned}
$$

where, $k_{\text {bus }}$ is constant.

$B_{\text {private }}$ is involvement fee as a fixed constant; consider the following:

$$
C_{\text {private }}^{0}\left(Q_{\text {private }}\right)=Q \frac{e^{U_{\text {brt }}}}{e^{U_{\text {brt }}}+e^{U_{\text {bus }}}} M_{\text {return }}
$$


is profit item returned to passengers; consider the following:

$$
\begin{aligned}
\sum_{i=1}^{n} B_{\text {subsidy }}^{i}+\sum_{i=1}^{n} B_{\text {other }}^{i}= & M_{\text {subsidy }} Q \frac{e^{U_{\text {bus }}}}{e^{U_{\text {brt }}}+e^{U_{\text {bus }}}} \\
& +N T_{\text {bus }} M_{\text {vehiclesubsidy }}
\end{aligned}
$$

is government subsidies related to public transportation volume and vehicles; consider the following:

$$
\sum_{i=n+1}^{m} f_{i} Q_{i}=Q \frac{e^{U_{\text {brt }}}}{e^{U_{\text {brt }}}+e^{U_{\text {bus }}}} f_{\text {brt }}
$$

is ticket fare of private capital company.

The last item $C_{\text {without }}^{0}(F)$ is the cost of the bus company related to departure frequency.

Then, the upper objective function can be written as follows:

$$
\begin{aligned}
\max _{f} S(f, F)= & \int_{0}^{Q} f(d) d w+B_{\text {private }} \\
& +Q \frac{e^{U_{\text {brt }}}}{e^{U_{\text {brt }}}+e^{U_{\text {bus }}}} M_{\text {return }} \\
& +r_{\text {subsidy }} Q \frac{e^{U_{\text {bus }}}}{e^{U_{\text {brt }}}+e^{U_{\text {bus }}}} \\
& +N T_{\text {bus }} r_{\text {vehiclesubsidy }} \\
& -Q \frac{e^{U_{\text {brt }}}}{e^{U_{\text {brt }}}+e^{U_{\text {bus }}}} f_{\text {brt }}-C_{\text {without }}^{0}(F) .
\end{aligned}
$$

The first-order and second-order partial derivatives of objective function were taken with respect to ticket price $f$ to get the values of $A, B$, and $C$. Consider

$$
\begin{aligned}
& A=\frac{\partial^{2} S(f, F)}{\partial^{2} f_{\text {brt }}}=k_{\text {brt }}^{2}+Q \frac{e^{U_{\text {brt }}} e^{U_{\text {bus }}}}{\left(e^{U_{\text {brt }}}+e^{U_{\text {bus }}}\right)^{3}} \\
& \text { - } \theta_{\text {brtfee }}\left[\theta_{\text {brtfee }}\left(e^{U_{\text {bus }}}-e^{U_{\text {brt }}}\right)\right. \\
& \left.\cdot\left(M_{\text {return }}-M_{\text {subsidy }}-f_{\text {brt }}\right)-2\left(e^{U_{\text {brt }}}+e^{U_{\text {bus }}}\right)\right] \text {; } \\
& B=\frac{\partial^{2} S(f, F)}{\partial f_{\text {brt }} \partial f_{\text {bus }}}=k_{\text {brt }} k_{\text {bus }}+Q \frac{e^{U_{\text {brt }}} e^{U_{\text {bus }}}}{\left(e^{U_{\text {brt }}}+e^{U_{\text {bus }}}\right)^{3}} \\
& \text { - } \theta_{\text {busfee }} \theta_{\text {brtfee }}\left(e^{U_{\text {brt }}}-e^{U_{\text {bus }}}\right)\left(M_{\text {return }}-M_{\text {subsidy }}\right. \\
& \left.-f_{\text {brt }}\right)+Q \frac{e^{U_{\text {brt }}} e^{U_{\text {bus }}}}{\left(e^{U_{\text {brt }}}+e^{U_{\text {bus }}}\right)^{2}} \theta_{\text {busfee }} \\
& C=\frac{\partial^{2} S(f, F)}{\partial^{2} f_{\text {bus }}}=k_{\text {bus }}^{2}+Q \frac{e^{U_{\text {brt }}} e^{U_{\text {bus }}}}{\left(e^{U_{\text {brt }}}+e^{U_{\text {bus }}}\right)^{3}} \theta_{\text {busfee }}^{2}\left(e^{U_{\text {brt }}}\right. \\
& \left.-e^{U_{\text {bus }}}\right)\left(-M_{\text {return }}+M_{\text {subsidy }}+f_{\text {brt }}\right) \text {. }
\end{aligned}
$$

If $\left(e^{U_{\text {bus }}}-e^{U_{\text {brt }}}\right)\left(M_{\text {return }}-M_{\text {subsidy }}-f_{\text {brt }}\right) \geq 0$, then $A \geq 0$, because the calibration coefficient of ticket price is negative.
Then, $\left(e^{U_{\text {bus }}}-e^{U_{\text {brt }}}\right) \geq 0,\left(M_{\text {return }}-M_{\text {subsidy }}-f_{\text {brt }}\right) \geq 0$ or $\left(M_{\text {return }}-M_{\text {subsidy }}-f_{\text {brt }}\right) \leq 0,\left(e^{U_{\text {bus }}}-e^{U_{\text {brt }}}\right) \leq 0$. Because $\left(e^{U_{\text {bus }}}-e^{U_{\text {brt }}}\right) \geq 0,\left(M_{\text {return }}-M_{\text {subsidy }}-f_{\text {brt }}\right) \geq 0$, the utility of bus is greater than that of BRT and benefits returned to passengers are greater than government subsidies and ticket fares, which is not suitable for the benefit requirements of private capital company. So, conditions $\left(M_{\text {return }}-M_{\text {subsidy }}-f_{\text {brt }}\right) \leq 0$ and $\left(e^{U_{\text {bus }}}-e^{U_{\text {brt }}}\right) \leq 0$ are chosen. That is, if the utility of BRT is greater than that of bus and benefits returned to passengers are less than government subsidies and ticket fares, then $A \geq$ 0 . The ticket price accepted most willingly by passengers is free $(f=0)$; then the constant items in $A, B$, and $C$ equal zero, and $A C-B^{2}$ is simplified as follows:

$$
\begin{aligned}
& A C-B^{2}=Q^{2} \frac{\left(e^{U_{\text {brt }}}\right)^{2}\left(e^{U_{\text {bus }}}\right)^{2}}{\left(e^{U_{\text {brt }}}+e^{U_{\text {bus }}}\right)^{5}} \\
& \cdot \theta_{\text {busfee }}^{2}\left[-4 \theta_{\text {brtfee }}\left(e^{U_{\text {bus }}}-e^{U_{\text {brt }}}\right)\right. \\
& \left.\cdot\left(-M_{\text {return }}+M_{\text {subsidy }}+f_{\text {brt }}\right)-\left(e^{U_{\text {brt }}}+e^{U_{\text {bus }}}\right)\right] .
\end{aligned}
$$

On the condition of $\left(M_{\text {return }}-M_{\text {subsidy }}-f_{\text {brt }}\right) \leq 0$, $\left(e^{U_{\text {bus }}}-e^{U_{\text {brt }}}\right) \leq 0$, the first item in the bracket of the above equation is positive. Only if $M_{\text {return }}-M_{\text {subsidy }}-f_{\text {brt }} \geq\left(e^{U_{\text {brt }}}+\right.$ $\left.e^{U_{\text {bus }}}\right) / 4 \theta_{\text {brtfee }}\left(e^{U_{\text {brt }}}-e^{U_{\text {bus }}}\right)$, that is, the difference between profit returned to passengers, government subsidies, and ticket fares is larger than (24) (the value is negative), then $A C-B^{2} \geq$ 0 . At this point, the upper objective function is a convex function.

Note. Since only the above conditions can ensure that the upper objective function is convex, intelligent algorithms such as genetic algorithms (GA) can be used to solve the problem, because these algorithms do not require objective function to be continuously differentiable or convex.

4.2. Solution Algorithm. Because the bilevel programming problem is NP-hard problem, it is difficult to obtain the global optimal value. Colson $[40,41]$ published a series of representative research results to solve systematically the solution problems of nonlinear bilevel programming models and the mathematical programming with equilibrium constraints. The methods to solve bilevel programming models are divided into two types: one type of method is to solve the optimal solution of the lower model under a given variable value of the upper model. The other type is to transform the bilevel programming model into a single programming model using the optimality conditions instead of lower level programming model, such as KKT [39] optimality conditions. Specific algorithms [39-46] include the pole searching algorithm, branch definition method, steepest descent method, complementary rotation algorithm and penalty function method, evolutionary algorithm (genetic algorithm, particle swarm optimization (PSO) algorithm, neural network, and ant colony algorithm), and simulated annealing algorithm.

Because intelligent algorithms such as genetic algorithms and simulated annealing algorithms do not require convexity and continuously differentiable properties of objective 
functions, these heuristic algorithms have a wide range of applications. According to the above analysis of model characteristics and convex programming optimality theory, KKT conditions can be used to change the bilevel programming model into a single level programming problem, and a genetic algorithm $[36,47,48]$ is used to solve the model.

The lower level model of bilevel optimization (14)-(17) has the equivalent form described by the KKT stable point problem as follows:

$$
\begin{aligned}
& q_{i, k} \leq T \operatorname{Cap}_{i, k}, \\
& F_{i, k}^{\min } \leq F_{i, k} \leq \frac{N T_{i, k}}{2 r t_{i, k}}, \\
& \lambda_{1}\left(q_{i, k}-T \operatorname{Cap}_{i, k}\right)=0, \\
& \lambda_{2}\left(F_{i, k}-F_{i, k}^{\min }\right)\left(F_{i, k}-\frac{N T_{i, k}}{2 r t_{i, k}}\right)=0, \\
& \nabla\left[Q \sum_{i} C_{i} \cdot \frac{e^{\theta V_{i}}}{\left.\sum_{i} e^{\theta V_{i}}-C_{\text {private }}^{0}\left(Q_{\text {private }}\right)\right]}\right. \\
& \quad+\lambda_{1} \nabla\left(q_{i, k}-T C_{i, k}\right) \\
& \quad+\lambda_{2} \nabla\left[\left(F_{i, k}-F_{i, k}^{\text {min }}\right)\left(F_{i, k}-\frac{N T_{i, k}}{2 r t_{i, k}}\right)\right] \\
& \quad+\mu_{1} \nabla\left(Q-\sum_{i, k} Q_{i, k}^{*}\left(f_{i, k}, F_{i, k}\right)\right)=0, \\
& \quad \lambda_{1} \geq 0, \mu_{1} \neq 0 ; i=\text { brt, bus. }
\end{aligned}
$$

Genetic algorithms first generate initial solutions randomly based on the fixed number of population and then search for the optimal solution. Each initial solution generated randomly has a corresponding individual (chromosome) in populations, and it is constantly optimized in the subsequent iterations (the progress is called "genetic"). Chromosomes are sorted in iterations based on the defined fitness function, the chromosomes with high fitness values are propagated to next generation, and the next generation of chromosomes is formed after the duplication of the previous generation. The algorithm converges to the optimum solution (local) during iterations.

The process is mainly divided into four steps.

Step 1 (initialization). A group of initial populations (private capital investment strategy) are generated randomly according to the range of variable constraints of private capital investment in public transportation.

Step 2 (choice). The objective function of the optimization model is chosen as the fitness function; roulette wheel selection is adopted to choose chromosomes as paternal copies to produce offspring, and the choice probability of chromosome depends on the fitness value. The selection probability is presented as follows:

$$
\operatorname{Pr}\left(\varphi_{i}\right)=\frac{\varphi_{i}}{\sum_{j \in s(t)} \varphi_{j}},
$$

where $\operatorname{Pr}\left(\varphi_{i}\right)$ is the probability selected as parental copy for chromosome $i$ and $\varphi_{i}$ is fitness value of chromosome $i$.

Step 3 (duplication). This step includes two stages, crossover and mutation. Crossover means that a cross point is generated randomly in encoded string position of the chromosome, and two new individual species are generated through cross exchange genes behind the cross point. Mutation is a complement operation which guarantees that all potential useful information should be covered, and mutation probability decides the mutation frequency.

Step 4 (termination judgment). Termination conditions (the number of iterations or convergence error) are set, and the feasible solution which the minimum objective function value corresponds to when the algorithm terminates is the optimal solution of the genetic algorithm. In the following section, a fixed number of iterations are adopted as the termination condition.

\section{Case Study}

5.1. Case Description. The local public transportation network in Jinan city, Shandong Province, China, was selected to test the model. According to the 2014 statistical yearbook [49], the urban population of Jinan was 4.33 million at the end of 2013. The total number of Jinan Public Traffic Company staff was more than 11,300 at the end of 2014, and there were more than 4400 vehicles in operation, 646 taxis in operation, and 210 bus routes (7 BRT routes included) with a total length of 3527.5 kilometers. The public transportation system carries more than 2.4 million passenger trips daily. The public transit mode share rate (excluding walking) reached $29.69 \%$. The transit network formed by BRT5 and bus line 49 between Jinan Railway Station and Yan-Shan Overpass was the focus of this model verification. These two lines are shown in Figure 1.

Parameters in the bilevel model were calculated and established based on the operation data from the Jinan Public Traffic Company. The calibration results are listed in Table 2.

5.2. Model Solution and Analysis. MATLAB was chosen to implement the model using the genetic algorithm in Section 4.2 under several comparable conditions, such as with and without the private capital involvement in public transportation, whether or not to consider the lower constraints, and whether or not to give some returns to passengers. The minimum ticket price in Table 2 was chosen as the specific cost passengers were willing to pay. The model results in different conditions are listed in Table 3.

For the three kinds of situations (without private capital, traditional private investment, and private capital investment in public transportation considering passenger value), when 
TABLE 2: Parameter values of bilevel programming model.

\begin{tabular}{|c|c|c|c|c|c|c|c|}
\hline Parameter & Value & Parameter & Value & Parameter & Value & Parameter [18] & Value \\
\hline$\overline{f_{\text {bus }}^{\min }}$ & 1 yuan & $N T_{\text {bus }}$ & 15 vehicles & $\beta_{\text {brtwalk }}$ & 30 yuan/hour & $\theta_{\text {busfee }}$ & -0.1 \\
\hline$f_{\text {bus }}^{\max }$ & 3 yuan & $N T_{\text {brt }}$ & 20 vehicles & $B_{\text {subsidy }}$ & 1 yuan/trip & $\theta_{\text {brtfee }}$ & -0.08 \\
\hline$f_{\mathrm{brt}}^{\min }$ & 2 yuan & $V_{\text {bus }}$ & $15 \mathrm{~km} /$ hour & $C_{\text {fixedbus }}$ & 3 yuan/vehicle $\cdot \mathrm{km}$ & $\theta_{\text {buswalk }}$ & -0.15 \\
\hline$f_{\mathrm{brt}}^{\max }$ & 5 yuan & $V_{\text {brt }}$ & $25 \mathrm{~km} /$ hour & $C_{\text {fixedbrt }}$ & 5 yuan/vehicle $\cdot \mathrm{km}$ & $\theta_{\text {brtwalk }}$ & -0.1 \\
\hline$F_{\text {bus }}^{\min }$ & 4 shifts/hour & $V_{\text {walk }}$ & $4 \mathrm{~km} /$ hour & $M_{\text {account }}$ & 20 yuan & $\theta_{\text {buswait }}$ & -0.2 \\
\hline$F_{\text {bus }}^{\max }$ & 15 shifts/hour & $\beta_{\text {bustravel }}$ & 20 yuan/hour & $B_{\text {private }}$ & 100 yuan/day & $\theta_{\text {brtwait }}$ & -0.15 \\
\hline$F_{\mathrm{brt}}^{\min }$ & 6 shifts/hour & $\beta_{\text {buswait }}$ & 25 yuan/hour & $r_{\text {return }}$ & 0.5 & $\theta_{\text {bustravel }}$ & -0.12 \\
\hline$F_{\mathrm{brt}}^{\max }$ & 20 shifts/hour & $\beta_{\text {buswalk }}$ & 25 yuan/hour & $r_{\text {private }}$ & $6 \%$ & $\theta_{\text {brttravel }}$ & -0.1 \\
\hline TCap bus & 50 persons/vehicle & $\beta_{\text {brttravel }}$ & 25 yuan/hour & $r_{\text {account }}$ & $10 \%$ & & \\
\hline TCap brt & 70 persons/vehicle & $\beta_{\text {brtwait }}$ & 30 yuan/hour & Q & 1500 trips & & \\
\hline
\end{tabular}

TABLE 3: Results.

\begin{tabular}{|c|c|c|c|c|c|c|}
\hline $\begin{array}{l}\text { Whether or not to } \\
\text { consider the lower } \\
\text { constraints }\end{array}$ & $\begin{array}{l}\text { Situation of private } \\
\text { capital involvement }\end{array}$ & $\begin{array}{l}\text { Bus ticket price } \\
\quad \text { (yuan) }\end{array}$ & $\begin{array}{l}\text { BRT ticket } \\
\text { price } \\
\text { (yuan) }\end{array}$ & $\begin{array}{l}\text { Bus departure } \\
\text { frequency } \\
\text { (shifts/hour) }\end{array}$ & $\begin{array}{l}\text { BRT departure } \\
\text { frequency } \\
\text { (shifts/hour) }\end{array}$ & $\begin{array}{l}\text { Objective value } \\
\text { (yuan) }\end{array}$ \\
\hline \multirow{3}{*}{$\begin{array}{l}\text { Not considering } \\
\text { lower constraints }\end{array}$} & Without private capital & 2.98 & 2 & 4 & 6 & 3891 \\
\hline & Traditional investment & 2.75 & 2 & 4 & 6 & 4152 \\
\hline & Investment with returns & 2.67 & 2 & 4 & 6 & 4187 \\
\hline \multirow{3}{*}{$\begin{array}{l}\text { Considering lower } \\
\text { constraints }\end{array}$} & Without private capital & 1 & 2 & 15 & 20 & 2737 \\
\hline & Traditional investment & 1 & 2 & 15 & 20 & 3457 \\
\hline & Investment with returns & 1 & 2 & 15 & 20 & 3488 \\
\hline
\end{tabular}

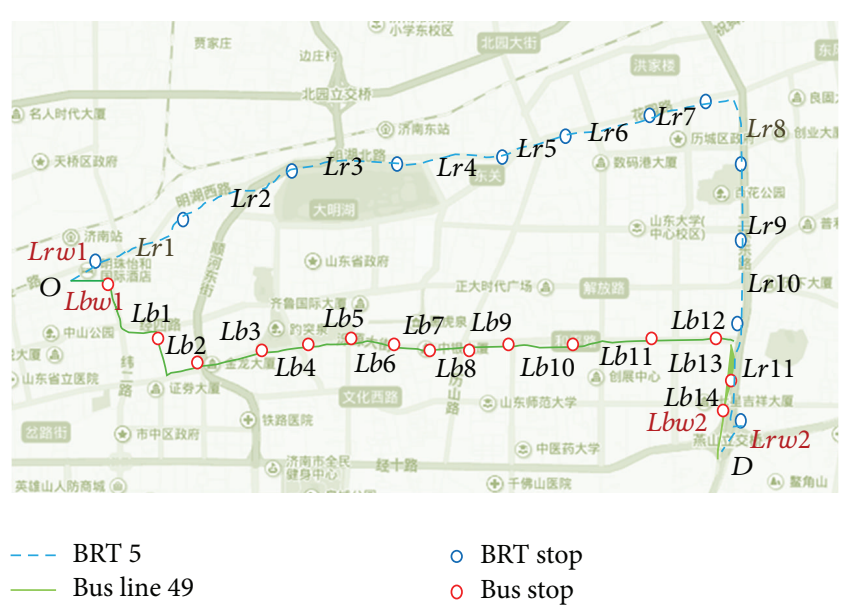

FIGURE 1: Distribution of chosen routes and stops. Note: $L r$ demonstrates the distance between stops of BRT5; $L b$ presents the distance between the stops of bus line $49 ; \mathrm{Lrw}$ is walk distance to BRT5; Lbw is walk distance to bus $49 ; \mathrm{O}$ is orientation and $\mathrm{D}$ is destination.

the lower objective constraints were considered, the upper objective value was reduced, the bus ticket prices were all reduced to one yuan, BRT departure frequency increased from six to 20 departures/hour, and the bus departure frequency increased from four to 15 departures/hour. This shows that when passenger travel cost is considered, travel cost creates passenger benefit in the form of reduced ticket prices and increased departure frequencies to reduce waiting time. The benefits in waiting time and ticket prices returned to passengers can be calculated as monetary value according to the model.

The objective values for the two cases of private capital investments were greater than the objective value without private investment both when the lower traveler cost constraint was not considered and when it was considered. This result shows that the total social benefit of public transportation systems increases with private capital investment. The objective values of private capital investment considering passenger value in different situations were greater than those of traditional investment, and the result shows that the investment method considering passenger value and returning some profits to passengers is superior to the traditional investment method without considering passenger value.

The bilevel programming model is reasonable for private capital investment in public transportation considering passenger value in the process of solution and results analysis. Specific parameters can be regulated and controlled based on the model in next step, and the returns strategy is worthy of further and more detailed discussion.

\section{Conclusions}

A bilevel programming quantitative evaluation model of private capital investment in public transportation considering passenger value was constructed in the paper. The model characteristics were then analyzed, a solution algorithm was designed, and the model validity was verified through the model characteristics and a sample analysis of Jinan public transportation. The results provide a theoretical basis for quantitatively analyzing the feasibility of private capital 
investment in public transportation and designing more efficient investment strategies.

Private capital investment is helpful to increase the total social benefits of the public transportation system, and the private investment method considering passenger value is superior to the traditional investment method. The above analysis shows that the competition among different traffic modes, the relationship among generalized travel costs, government subsidies, and returns to passengers should be considered. Only in this way can the success rate of private capital investment in public transportation be improved efficiently.

On the basis of the model established in this paper, more detailed research can be developed. For instance, the sample case is a specific numerical solution under given parameter values. In fact, each parameter is not certain. This is the uncertainty bilevel programming problem which will be explored in future research. Additionally, the strategies for private capital company to return profits to passengers need further development. The bilevel programming model established in this paper laid the foundation for future research.

\section{Conflict of Interests}

The authors declare that there is no conflict of interests regarding the publication of this paper.

\section{Acknowledgments}

This research was supported by the National Natural Science Foundation of China (Grant nos. 51338008 and 51308015), National Basic Research Program of China (no. 2012CB725403), and China Scholarship Council (File no. 201506540030). The authors give thanks to Jinan Public Traffic Company for operation data. Special thanks are due to Dr. Yao-Jan Wu and Mr. Payton Crooke at the University of Arizona for valuable comments and English assistance.

\section{References}

[1] G. Malandraki, I. Papamichail, M. Papageorgiou, and V. Dinopoulou, "Simulation and evaluation of a public transport priority methodology," Transportation Research Procedia, vol. 6, pp. 402-410, 2015.

[2] R. Matsunaka, T. Oba, D. Nakagawa, M. Nagao, and J. Nawrocki, "International comparison of the relationship between urban structure and the service level of urban public transportationa comprehensive analysis in local cities in Japan, France and Germany," Transport Policy, vol. 30, pp. 26-39, 2013.

[3] R. Osei-Kyei and A. P. C. Chan, "Review of studies on the Critical Success Factors for Public-Private Partnership (PPP) projects from 1990 to 2013," International Journal of Project Management, vol. 33, no. 6, pp. 1335-1346, 2015.

[4] Á. Costa, "The organisation of urban public transport systems in Western European metropolitan areas," Transportation Research Part A: Policy and Practice, vol. 30, no. 5, pp. 349-359, 1996.

[5] C. Winston, "Government failure in urban transportation," Fiscal Studies, vol. 21, no. 4, pp. 403-425, 2000.

[6] F. R. Medda, G. Carbonaro, and S. L. Davis, "Public private partnerships in transportation: some insights from the European experience," IATSS Research, vol. 36, no. 2, pp. 83-87, 2013.
[7] R. Mu, M. D. Jong, and J. Koppenjan, "The rise and fall of PublicPrivate Partnerships in China: a path-dependent approach," Journal of Transport Geography, vol. 19, no. 4, pp. 794-806, 2011.

[8] S. B. Zhang, Y. Gao, Z. Feng, and W. Z. Sun, "PPP application in infrastructure development in China: institutional analysis and implications," International Journal of Project Management, vol. 33, no. 3, pp. 497-509, 2015.

[9] E. M. Fox, An Anti-Monopoly Law for China-Scaling the Walls of Protectionist Administrative Restraints, Beijing Law Review, 2006.

[10] Press Conference on Beijing Municipality Giving Priority to the Development of Public Transportation, "Accelerating the construction of intelligent traffic, and easing traffic congestion," Chinese Law and Government, vol. 41, no. 6, pp. 67-82, 2008.

[11] W. Cox, "Competitive participation in U. S. public transport: special interests versus the public interest," in Proceedings of the 8th International Conference on Competition and Ownership in Land Passenger Transport (Thredbo 8 '03), pp. 1-24, Rio de Janeiro, Brazil, September 2003.

[12] J. K. Roehrich, M. A. Lewis, and G. George, "Are public-private partnerships a healthy option? A systematic literature review," Social Science \& Medicine, vol. 113, pp. 110-119, 2014.

[13] Y. L. Xu, J. F. Y. Yeung, A. P. C. Chan, D. W. M. Chan, S. Q. Wang, and Y. Ke, "Developing a risk assessment model for PPP projects in China-a fuzzy synthetic evaluation approach," Automation in Construction, vol. 19, no. 7, pp. 929-943, 2010.

[14] Y. J. Ke, S. Q. Wang, A. P. C. Chan, and P. T. I. Lam, "Preferred risk allocation in China's public-private partnership (PPP) projects," International Journal of Project Management, vol. 28, no. 5, pp. 482-492, 2010.

[15] C. Willoughby, "How much can public private partnership really do for urban transport in developing countries?" Research in Transportation Economics, vol. 40, no. 1, pp. 34-55, 2013.

[16] T. M. Nisar, "Value for money drivers in public private partnership schemes," International Journal of Public Sector Management, vol. 20, no. 2, pp. 147-156, 2007.

[17] H. Yang, H. Yan Kong, and Q. Meng, "Value-of-time distributions and competetive bus services," Transportation Research Part E: Logistics and Transportation Review, vol. 37, no. 6, pp. 411-424, 2001.

[18] Y. Q. Xue, H. Z. Guan, H. M. Qin et al., "The study on key factors influencing public transport share rate based on disaggregate model-Jinan as an example," in Proceedings of the 14th COTA International Conference of Transportation Professionals, pp. 3628-3640, ASCE, Changsha, China, July 2014.

[19] R. Tang and H. Sun, "Discussion on involvement modes and fields of private capital introduced into transportation industry," Finance \& Accounting for Communication, vol. 8, pp. 10-16, 2012 (Chinese).

[20] P. B. Seybold, R. T. Marshak, and J. M. Lewis, The Customer Revolution: How to Thrive when Customers are in Control, Crown Business, New York, NY, USA, 2001.

[21] P. C. Verhoef and K. N. Lemon, "Successful customer value management: key lessons and emerging trends," European Management Journal, vol. 31, no. 1, pp. 1-15, 2013.

[22] M. S. Kahreh, M. Tive, A. Babania, and M. Hesan, "Analyzing the applications of customer lifetime value (CLV) based on benefit segmentation for the banking sector," Procedia-Social and Behavioral Sciences, vol. 109, pp. 590-594, 2014.

[23] W. Ulaga and S. Chacour, "Measuring customer-perceived value in business markets: a prerequisite for marketing strategy 
development and implementation," Industrial Marketing Management, vol. 30, no. 6, pp. 525-540, 2001.

[24] W. Ulaga, "Customer value in business markets: an agenda for inquiry," Industrial Marketing Management, vol. 30, no. 4, pp. 315-319, 2001.

[25] S. A. Brown, Customer Relationship Management: A Strategic Imperative in the World of E-Business, John Wiley \& Sons, 2000.

[26] T. J. Gerpott, W. Rams, and A. Schindler, "Customer retention, loyalty, and satisfaction in the German mobile cellular telecommunications market," Telecommunications Policy, vol. 25, no. 4, pp. 249-269, 2001.

[27] J.-S. Chou and C.-P. Yeh, "Influential constructs, mediating effects, and moderating effects on operations performance of high speed rail from passenger perspective," Transport Policy, vol. 30, pp. 207-219, 2013.

[28] W. G. Wong, B. M. Han, L. Ferreira, X. N. Zhu, and Q. X. Sun, "Evaluation of management strategies for the operation of high-speed railways in China," Transportation Research-Part A: Policy and Practice, vol. 36, no. 3, pp. 277-289, 2002.

[29] M. Wei, B. Sun, and W. Z. Jin, "A bi-level programming model for uncertain regional bus scheduling problems," Journal of Transportation Systems Engineering and Information Technology, vol. 13, no. 4, pp. 106-113, 2013.

[30] X. Y. Zhao and J. Q. Yang, "Research on the Bi-level programming model for ticket fare pricing of urban rail transit based on particle swarm optimization algorithm," Procedia-Social and Behavioral Sciences, vol. 96, pp. 633-642, 2013, Proceedings of the 13th COTA International Conference of Transportation Professionals.

[31] Moshe, B. Akiva, M. Bierlaire et al., Discrete Choice Analysis: The Theory and Application to Travel Demand, MIT Press, Cambridge, Mass, USA, 2010.

[32] K. E. Train, Discrete Choice Methods with Simulation, Cambridge University Press, Cambridge, UK, 2nd edition, 2009.

[33] X. Lai and J. Li, "Modelling stochastic route choice behaviours with a closed-form mixed Logit model," Mathematical Problems in Engineering, vol. 2015, Article ID 729089, 9 pages, 2015.

[34] B. F. Shi, J. Wang, J. Y. Qi, and Y. Q. Cheng, "A novel imbalanced data classification approach based on logistic regression and Fisher discriminant," Mathematical Problems in Engineering, vol. 2015, Article ID 945359, 12 pages, 2015.

[35] J. Li, X. Lai, and Z. Yu, "A paired combinatorial logit route choice model with probit-based equivalent impedance," Journal of Transportation Systems Engineering and Information Technology, vol. 13, no. 4, pp. 100-105, 2013.

[36] T. Yokota, M. Gen, Y. Li, and C. E. Kim, "A genetic algorithm for interval nonlinear integer programming problem," Computers \& Industrial Engineering, vol. 31, no. 3-4, pp. 913-917, 1996.

[37] R. Mulero and B. Layton, "Two-dimensional Minkowski sum optimization of ganged stamping blank layouts for use on pre-cut sheet metal for convex and concave parts," Journal of Manufacturing Systems, vol. 26, no. 1, pp. 44-52, 2007.

[38] S. Boyd and L. Vandenberghe, Convex Optimization, Cambridge University Press, Cambridge, UK, 2009.

[39] S. Sinha and S. B. Sinha, "KKT transformation approach for multi-objective multi-level linear programming problems," European Journal of Operational Research, vol. 143, no. 1, pp. 1931, 2002.

[40] B. Colson, Mathematical programs with equilibrium constraints and nonlinear bi-level programming problems [M.S. thesis], University of Namur, Namur, Belgium, 1999.
[41] B. Colson, P. Marcotte, and G. Savard, "A trust-region method for nonlinear programming: algorithm and computational experience," Computational Optimization and Applications, vol. 30, no. 3, pp. 211-227, 2005.

[42] I. A. Baky, "Solving multi-level multi-objective linear programming problems through fuzzy goal programming approach," Applied Mathematical Modelling, vol. 34, no. 9, pp. 2377-2387, 2010.

[43] B. Colson, P. Marcotte, and G. Savard, "An overview of bilevel optimization," Annals of Operations Research, vol. 153, pp. 235256, 2007.

[44] S. Demps, Foundation of Bi-Level Programming, Kluwer Academic Publishers, Dordrecht, The Netherlands, 2003.

[45] X. Deng, A. Migdalas, P. M. Pardalos et al., "Complexity issues in Bi-level linear programming," in Multi-Level Optimization: Algorithms and Applications, pp. 149-164, Kluwer Academic Publishers, Dordrecht, The Netherlands, 1998.

[46] H. Yang and M. G. Bell, “Transport bi-level programming problems: recent methodological advances," Transportation Research B: Methodological, vol. 35, no. 1, pp. 1-4, 2001.

[47] J. W. Gu, M. Z. Gu, and X. S. Gu, "A mutualism quantum genetic algorithm to optimize the flow shop scheduling with pickup and delivery considerations," Mathematical Problems in Engineering, vol. 2015, Article ID 387082, 17 pages, 2015.

[48] D. E. Goldberg, Genetic Algorithms in Search, Optimization and Machine Learning, Addison-Wesley, Reading, Mass, USA, 1989.

[49] Jinan Bureau of Statistics, Year Book of Jinan City, China Statistic Press, Beijing, China, 2015 (Chinese). 


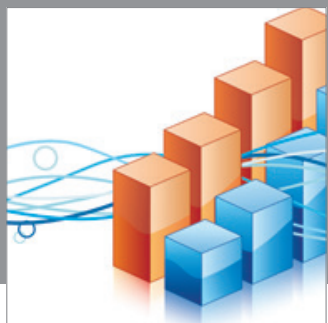

Advances in

Operations Research

mansans

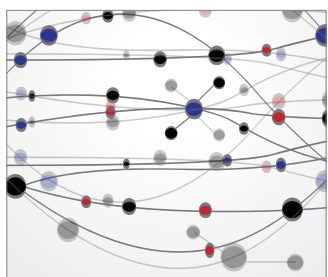

The Scientific World Journal
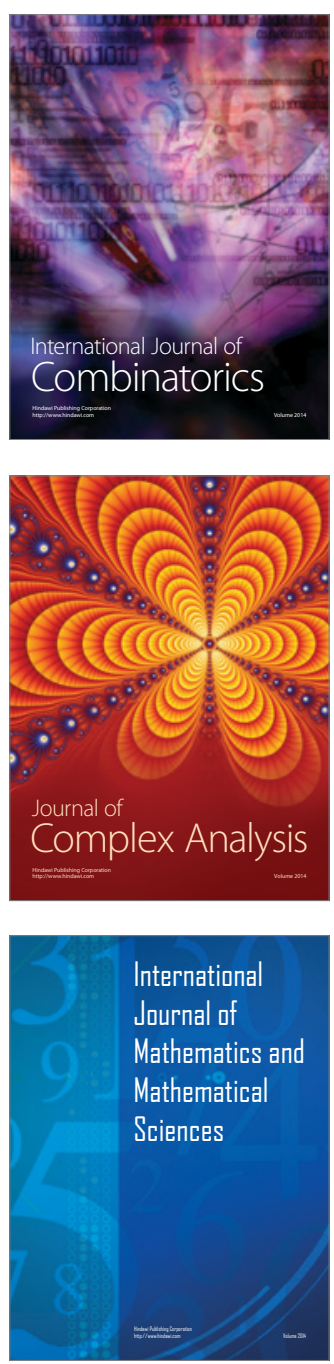
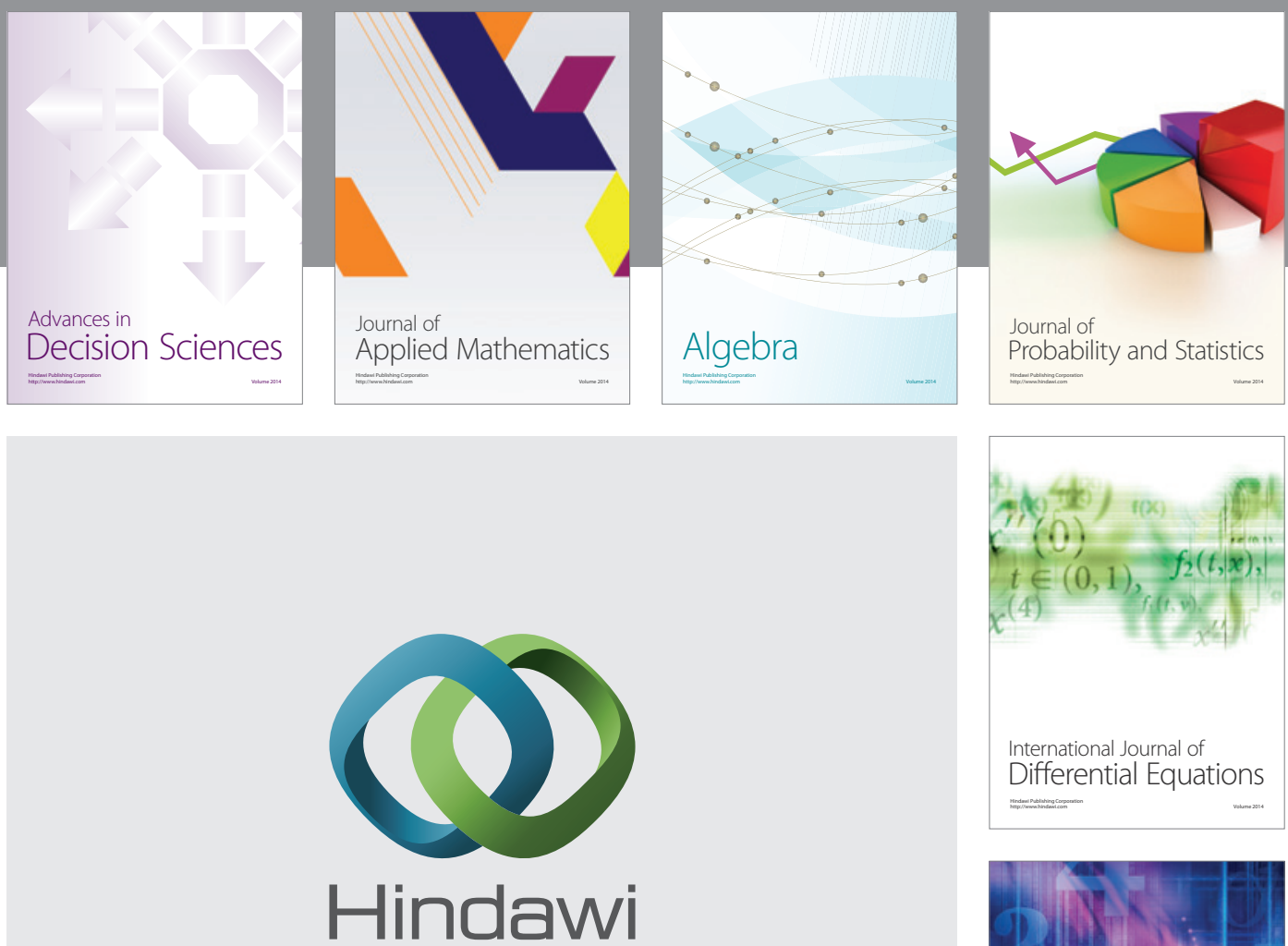

Submit your manuscripts at http://www.hindawi.com
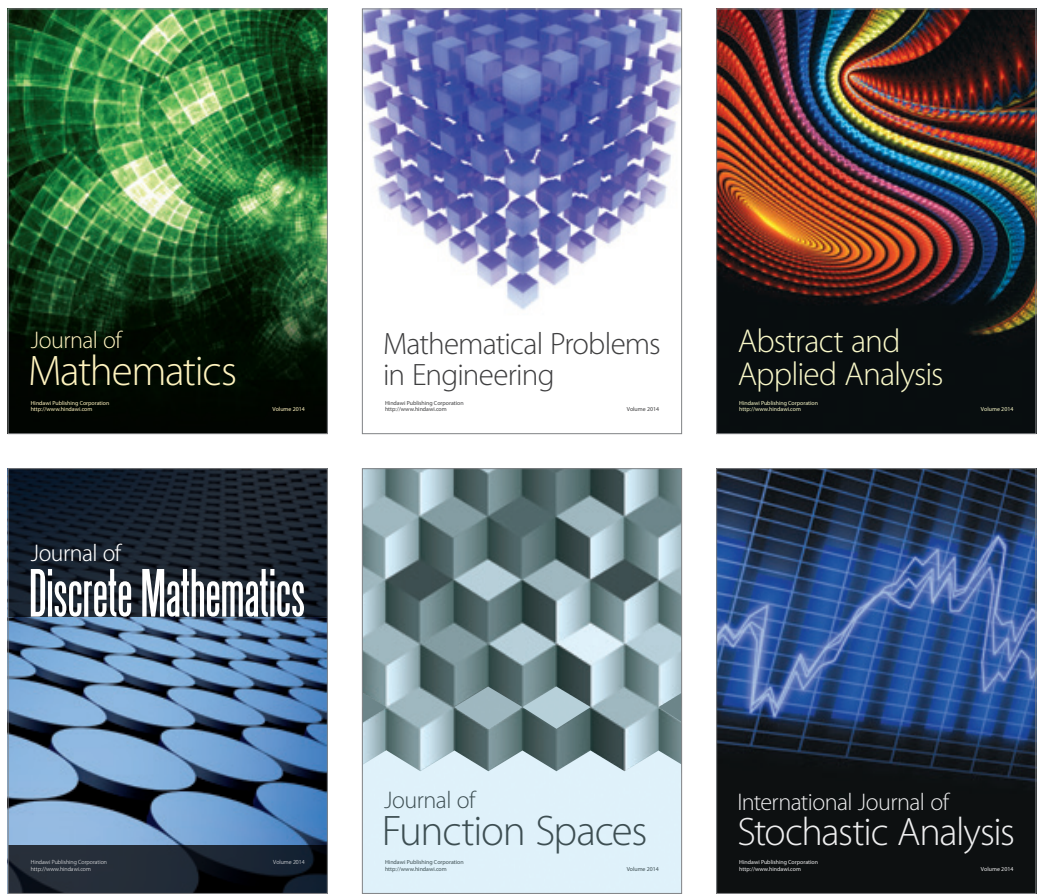

Journal of

Function Spaces

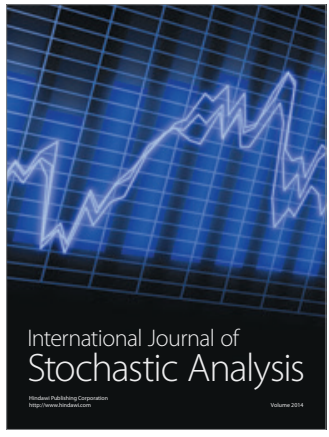

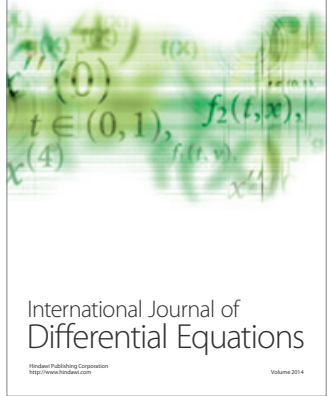
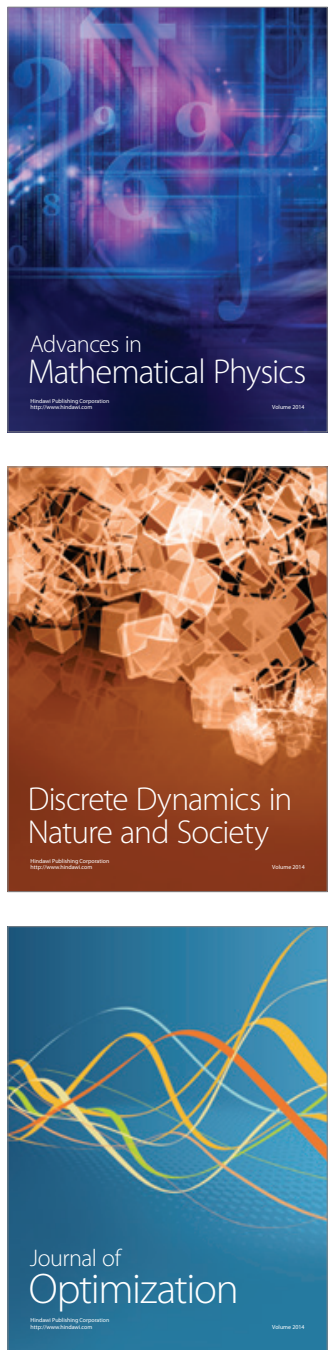